\title{
Biological Control of Weeds: Is it Safe? ${ }^{1}$
}

\author{
Carey Minteer, Eutychus Kariuki, and James Cuda ${ }^{2}$
}

This document is intended to provide information for Extension agents and the general public on the process of developing and implementing a biological control of weeds program and explain the processes and regulations that ensure that biological control of invasive plants is a safe practice.

Invasive plants arenon-native plant species that cause harm in their introduced range. Harm can be classified as negative impacts to the invaded environment, the economy, and/or human/animal health. Not all non-native species are considered invasive because many do not cause harm in the area of introduction. Invasive species can harm our world in numerous ways. These plant species can crowdout and outcompete native plants (Qi et al. 2014; Schultheis \& MacGuigan 2018) (Figure 1) and reduce habitat and forage for our native wildlife. Invasive plant species can also damage our economy by obstructing navigable waterways (Asmare 2017), interfering with recreational activities such as angling (Brown and Maceina 2002), and impacting productivity of our farms and ranches (Salaudeen et al. 2013). Many invasive plants can be detrimental to human and animal health by causing allergic reactions, being toxic if ingested, or inflicting physical injuries through sharp spines or thorns (Lazzaro et al. 2018).

Once an invasive plant is present, control is important to lessen the damage to the environment. We can use many different strategies to control invasive species. Mechanical, chemical, cultural, and biological control practices can be used alone or in combination to control or mitigate the effects of invasive plants. The success of each of these methods depends on the characteristics of the invaded area and the target plant, and generally a combination of practices is required to have effective control. Each method has its own unique set of pros and cons.

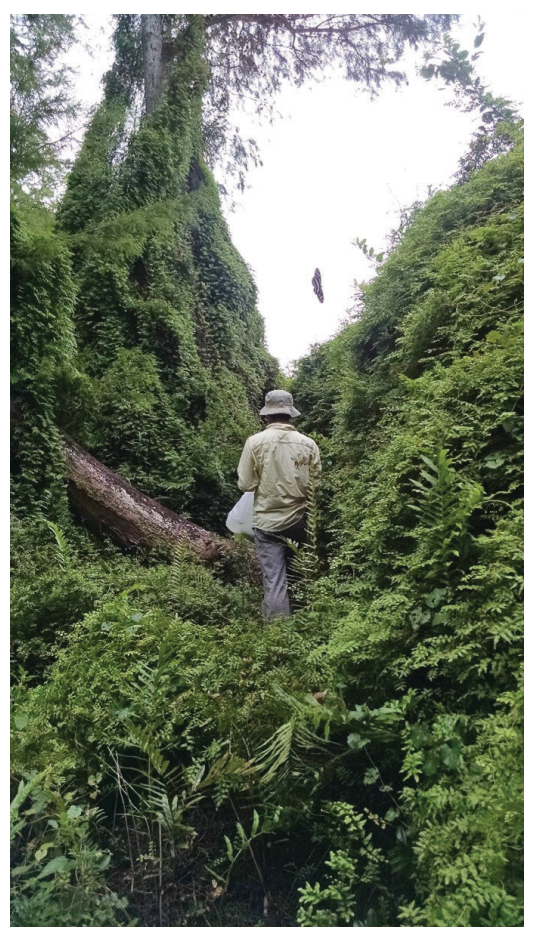

Figure 1. Old World climbing fern invading a tree island at Loxahatchee National Wildlife Refuge. Vines climb up and over trees and other vegetation, shading out the plants underneath. Credits: Carey R. Minteer, UF/IFAS

1. This document is ENY2072, one of a series of the Entomology and Nematology Department, UF/IFAS Extension. Original publication date December 2021. Visit the EDIS website at https://edis.ifas.ufl.edu for the currently supported version of this publication.

2. Carey Minteer, assistant professor; Eutychus Kariuki, post-doctoral researcher; Entomology and Nematology Department, Indian River Research and Education Center; and James Cuda, emeritus professor, Entomology and Nematology Department, UF/IFAS Extension, Gainesville, FL 32611.

The Institute of Food and Agricultural Sciences (IFAS) is an Equal Opportunity Institution authorized to provide research, educational information and other services

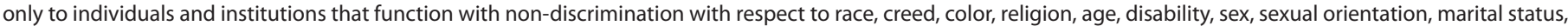

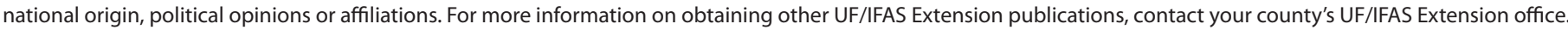
U.S. Department of Agriculture, UF/IFAS Extension Service, University of Florida, IFAS, Florida A \& M University Cooperative Extension Program, and Boards of County Commissioners Cooperating. Andra Johnson, dean for UF/IFAS Extension. 
Mechanical control is the physical removal or disruption of the target weed. Examples of mechanical control include mowing, prescribed fire, harvesting, or pulling. Mechanical controls work well in some areas but can lead to unintended impacts on other species. Mechanical controls, such as prescribed fire, can be used on large areas in suitable conditions by trained and knowledgeable persons. Other mechanical controls, such as hand-pulling, can be effective in small areas but often are time-consuming and laborious.

Chemical control is the use of herbicides to control a weed (Figure 2). There is a vast array of chemicals that have been developed and labeled for controlling invasive plant species. Herbicides have different modes of action, can be broad spectrum or selective, and can be classified as systemic or contact. Many of these chemicals are labeled for home/ general use, whereas some of them require a license. These chemicals can be effective against invasive plants if used properly, but non-target impacts are possible. Care must be taken to limit exposing non-targets. Herbicides are also difficult to use in sensitive habitats, such as waterways and areas that contain protected species, and can be very expensive when used across large areas. Always follow label directions when applying a pesticide and contact your local Extension agent for more information on application practices and recommendations. More information on herbicides can be found in the EDIS publication: Florida Homeowner Herbicide Guide: Considerations, Applications, and Selection (https://edis.ifas.ufl.edu/publication/EP575).

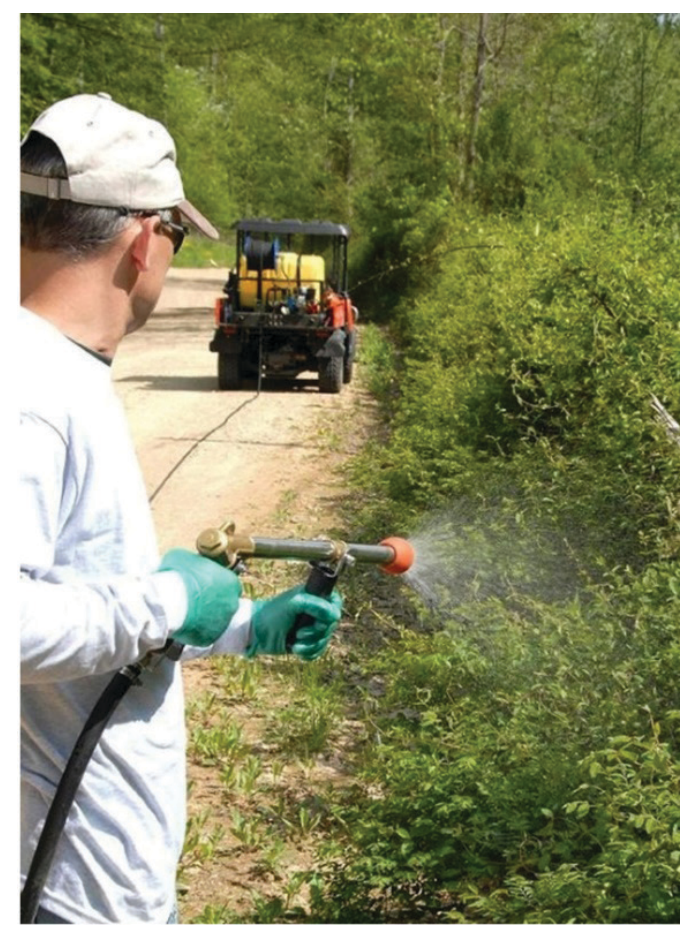

Figure 2. Application of herbicides for weed control. Credits: Steve Manning, Invasive Plant Control, Bugwood.org
Cultural control involves modification of a weed's habitat. Examples include draining a pond, installing weed barriers, and mulching. Each of these examples of cultural control removes something that a plant needs to survive. For example, draining a pond removes the water essential for the survival of an aquatic plant. Weed barriers and mulches remove sunlight from newly sprouting plants. Cultural control can be very effective on small areas, but as the area infested becomes larger, the cost and labor of implementing cultural control tactics increase greatly.

Classical Biological control of invasive plants is the use of imported arthropods (e.g., insects and mites) or pathogens to control the target weed. These organisms, which are called natural enemies, are found in the native range of the invasive plant and are often introduced into the invaded area to provide the same level of natural regulation that is seen in the native range. Determining the safety of candidate biological control agents before release into the environment is the main goal of scientists involved in the process. Biological control is safe because the natural enemies selected for release are host specific, environmentally friendly given that the use of biological control often can reduce the need for other control methods that are often associated with non-target impacts, and sustainable because once biological control agents are established on the landscape, they reproduce and move into new areas on their own.

Once natural enemies are established, biological control can have a high return on investment with economic returns of successful projects ranging from 5:1 to $>1,000: 1$ (Naranjo et al. 2015). However, the upfront costs of biological control can be very high before the first biological control agents are even released. The process of biological control is also very slow, in both the researching of potential agents and in the amount of time it takes for the natural enemies to successfully control the target. Here we describe how a biological program for control of weeds is developed and implemented and explain the processes and regulations associated with the practice.

\section{Target selection}

The first step in any biological control program is to select an appropriate target. Not all targets are amenable to the development of a biological control program. A good target is a non-native weed that is especially problematic, is not a conflict of interest for control (i.e., a crop or horticulturally important species), and generally is not closely related to native or economically important plant species in the invaded range. Because biological control relies on 
host-specific natural enemies (organisms that only feed/ attack and reproduce on the target plant), a target that is closely related to many native or economically important plants often can be problematic. Determining this relatedness to the target is important because plant species that are closely related to one another often will be very similar physically and chemically. Organisms that reproduce on multiple plant species are not host specific and therefore cannot be considered for use as biological control agents.

Another important piece of information to determine is the exact native range of the target species. Sometimes the exact native range is unknown. This is especially true with weeds that are cosmopolitan (i.e., present in multiple parts of the world). The native range of a target weed can be revealed by scientific literature searches of historical presence and introductions to new areas. The native range also can be determined through genetic methods (Amsellem et al. 2000). Once the native range is delineated, a search for potential biological control agents can begin because the native range of the target is where the highest diversity of natural enemies will occur.

\section{Foreign Exploration}

Natural enemies of a target plant are found in the native range of the weed in a process called foreign exploration or native range exploration. Researchers travel to the native range of a weed target and conduct surveys in the region. These surveys usually are performed with local research collaborators familiar with the native range of the target weed. Insects or pathogens observed attacking the target plant are collected. These insects are brought back to specialized laboratories in the United States called containment (or quarantine) laboratories (Figure 3). These laboratories are specifically designed to contain arthropods, plants, and other organisms such as fungi so that they do not escape into the environment. More information on containment/quarantine laboratories can be found in the EDIS publication: Biological Control Containment Facilities in Florida (https://edis.ifas.ufl.edu/publication/IN509).

Once the natural enemies are introduced into the containment laboratory, clean colonies (colonies free from other species) of these insects are established, and representative specimens are sent to taxonomic experts for identification. After an identification is made, a literature search is conducted for records of host plants and any other information on the natural enemy or its relatives that may be relevant (e.g., evidence of toxicity, ability to spread plant pathogens, allergenic to people, etc.).

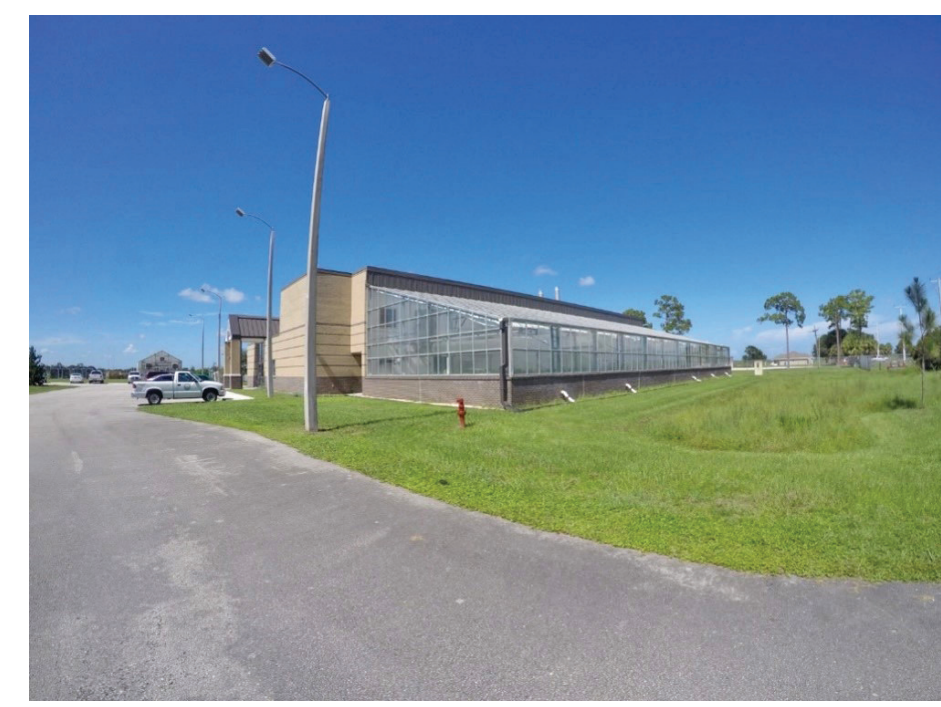

Figure 3. UF/IFAS Hayslip Biological Control Research and Containment Laboratory, a USDA-APHIS inspected containment facility in Fort Pierce, FL that allows for the safe testing of arthropod biological control agents for weeds or arthropods.

Credits: Carey R. Minteer, UF/IFAS

Often collaborators in the native range of the weed can help prioritize insect and other arthropod species for importation into containment labs in the United States (Minteer 2020 et al.). Not all organisms found on the target plant will be useful as biological control agents. For example, some arthropods may be polyphagous (feed on many species of plants), cause allergic reactions in people, cause harm to livestock, or vector plant pathogens. Conducting biological control research in the invaded range can be expensive and difficult due to space limitations in the containment labs. It is therefore important to import only the best candidates for biological control into containment labs in the introduced range of the pest. The best candidates to introduce are species that are non-toxic, that will likely have a limited host range (based on surveys for the organism on neighboring plants and literature reviews of the candidate or its congeners), and that do not have reported incidences of being pestiferous.

Once a potential biological control organism is imported into the containment lab, host range testing is initiated. To determine the fundamental host range (all plants that could be used as a host) (Sheppard et al. 2005), scientists conduct host range testing using updated versions of the centrifugal testing method (Wapshere 1974) that are based on testing plant species that are related to the target. In the United States, test plants are selected based on a series of categories that are outlined in the Technical Advisory Group for Biological Control Agents of Weeds (TAG) manual(USDAAPHIS 2019) (Table 1). Countries other than the United States also test host ranges, but guidelines vary by country (Sheppard et al. 2005). 
Table 1. Technical Advisory Group for Biological Control Agents of Weeds guidelines for plants that should be included in host range testing of candidate biological control agents of weeds in the United States.

\begin{tabular}{|l|l|}
\hline & \multicolumn{1}{|c|}{ Test Species } \\
\hline Category 1 & Target weed (including varying genetic types) \\
\hline Category 2 & Other plants in the same genus \\
\hline Category 3 & Other plants in the same family/subfamily \\
\hline Category 4 & $\begin{array}{l}\text { Threatened and endangered plants in the same } \\
\text { family }\end{array}$ \\
\hline Category 5 & $\begin{array}{l}\text { Other plants in the same order that have } \\
\text { phylogenetic, morphological, or chemical similarities } \\
\text { to the target }\end{array}$ \\
\hline Category 6 & $\begin{array}{l}\text { Plants in other orders that have morphological or } \\
\text { chemical similarities to the target }\end{array}$ \\
\hline Category 7 & $\begin{array}{l}\text { Plants that have been reported as a host for the } \\
\text { candidate biological control agent or its close } \\
\text { relatives }\end{array}$ \\
\hline
\end{tabular}

Depending on the taxonomic group to which your target belongs, this plant test list can get lengthy, especially if many species in the same genus and/or family occur in the invaded range. In the continental United States, test plant species are chosen from plant species that occur in all of North America.

No-choice/starvation tests are the first tests to be conducted during host-range testing. In these tests, a candidate biological control agent is placed on a non-target plant in a cage. This test is extremely conservative. It provides no other food source other than the non-target test plant. The candidate biological control agents can either feed on the test plant or die of starvation. To ensure that the lack of a suitable food source/host plant is the cause of death of an agent being tested and not some other factor (e.g., heat, dryness, cold), control test cages are used. The control test cages are set up with the target invasive plant (a known host/food source) and the candidate agent. These control test cages are placed near the non-target test plant cages in the same lab/greenhouse. If the candidate agents in the control test cage(s) die, it is due to some other factor (e.g., heat, dryness, cold) and not lack of a suitable host/food. If death of the agents in the control test cage occurs, the test is repeated.

\section{Choice Tests}

If a candidate biological control agent feeds and reproduces on a non-target plant in a no-choice test, choice tests are conducted. Choice testsare controlled, experimental tests that allow an insect to make a choice between two (paired choice) or more (multiple-choice) plant species: the nontarget(s) of interest and the target plant. In the choice tests, plant species are put into a closed cage. A group of study insects is placed in the center of the cage, equidistant from the plants. The insects are then monitored over time to determine which plant the insects choose to move towards and to monitor for feeding, egg laying, and any development that may occur. The results of choice tests can inform researchers if insects are likely to occur on the non-target plants outside of the lab if released.

\section{Multigeneration Tests}

If feeding and/or reproduction of a candidate biological control agent occurs during the no-choice tests, multigeneration tests are conducted. Multigeneration tests are very similar to no-choice tests, in that only one plant species is provided for the candidate biocontrol agent. However, unlike no-choice tests, multigeneration tests will monitor feeding and reproduction over the course of multiple generations of the insects being tested. In this type of test, the researcher is most interested in determining how long an insect species can sustain a population on a non-target. If a candidate biological control agent survives well on non-targets for multiple generations and prefers the non-target plant over the target plant in choice tests, it is eliminated from consideration as a biological control agent. An exception to this elimination is if the non-target plant in question is also considered an invasive species and in need of control.

\section{Host Range (Lab vs. Field)}

Tests like those conducted inside a lab are extremely conservative and can overestimate the host range of these insects. This is due to the nature of the tests. Conditions inside a lab and in a cage are very different from those in the world outside of the lab. Outside of the lab, an insect would have the freedom of movement and would never be confined to just one plant. With this movement comes the ability to choose a plant on which to feed and reproduce. Many factors go into this choice. Visual, olfactory (smell), and tactile cues go into recognizing a plant as a host (Ahmad 2012). A cage in the lab confines an insect to one plant species. If an insect feeds and reproduces on a plant under this situation, the plant is considered in the insect's fundamental host range. The fundamental host range is basically the plant species that the insect has the biological ability to feed and reproduce upon. However, the fundamental host range is often much wider than the ecological host range. The ecological host range(or field host specificity) consists of the plant species that an insect uses to feed and reproduce upon outside of the lab. The ecological host range is often much narrower than the 
fundamental host range because the insects are free to move and use environmental cues to recognize a plant as a host. Scientists can estimate the ecological host range of an insect by conducting choice tests as described above. If insects are found to have a sufficiently narrow host range in lab testing and are approved for release, scientists often conduct field host specificity tests after release.

\section{Field Host Specificity Tests}

Field host specificity tests provide evidence that lab-based tests accurately predicted the host range of the biocontrol agents in the field on un-caged plants. In these experiments, plants that were fed upon by the biological control agents in the no-choice lab tests are used as test species. Similarly sized test plants are placed in the field equidistant from each of their neighbors. Small groups of the biological control agents are placed under each test plant. Often these biological control agents are marked or labeled in some way to assess movement between the plant species. The plants are then assessed for presence of the biocontrol agents and evidence of insect feeding and/or reproduction over time.

\section{Other Lab Tests}

Host range tests are, arguably, the most important tests that are conducted during this process. However, many other experiments need to be conducted in order to determine that a biological control agent is safe and well matched to the environment in the new range. Firstly, we need to know what species of natural enemy we are testing.

Natural enemies that are selected for future study as biological control agents are often not known to science when they are collected. Therefore, getting a proper identification of the organism is very important. Biological control scientists partner with taxonomists who have expertise in the identification and description of arthropods and pathogens to accomplish this task.

Details on the biology of these organisms are not only important for establishing lab colonies but also for identifying field release sites. Identification of viable release sites includes determining the range of temperatures at which the organisms will survive and develop, and gathering information on where, when, and how they reproduce. Information like this can help determine where a biological control may survive in the introduced range.

With any introduction of a new species into an environment, there is some level of risk, but biological control scientists are very good at minimizing these risks.
Biological control scientists select safe, host-specific organisms to release and welcome governmental oversight over the process. More information on governmental oversight over biological control programs can be found in the EDIS publication: How Scientists Obtain Approval to Release Organisms for Classical Biological Control of Invasive Weeds (https://edis.ifas.ufl.edu/publication/IN607). The safety of a biological control strategy is determined by the tests and experiments described here. Even with governmental oversight and scrupulous science, there is still a small amount of risk involved. Forthis level of risk to be considered acceptable, a benefit must be present. The benefit in this case is the potential for control of the target weed.

Biocontrol scientists conduct tests to determine the amount of impact that a biological control agent will have on a target weed. Data are collected on where, what kind, and how much damage is done to the target. Data also are collected on how this damage impacts the growth and reproduction of the target. A biological control agent does not have to kill a target in order to be effective. Biological control agents that slow/stop the growth or reproduction of the target weed are useful for control of the species because they limit the target's ability to compete with native plants.

\section{Special Consideration Testing}

Sometimes it is necessary to conduct additional tests to ensure safety. These tests vary depending on the species of insect. Insect groups that have the ability to spread plant pathogenssuch as those in the orders Hemiptera and Thysanoptera will need to be tested to determine that the species is not a vector of plant pathogens (Overholt et al. 2015). Evidence documenting an organism's safety for humans and animals is also very important. Biological control agents that are determined to be unsafe for humans or livestock (e.g., stinging hairs, toxic if ingested) will not be approved for release (Cuda 2016; Boevé et al. 2018).

Once all of the necessary lab tests are conducted, the scientists write a petition summarizing their results and background information. This petition is submitted to USDA-APHIS and goes through a lengthy approval process (often several years long) that involves government regulators, government and university scientists from the United States, Canada, and Mexico, Native American tribes, and the general public. This approval process is outlined in the EDIS publication: How Scientists Obtain Approval to Release Organisms for Classical Biological Control of Invasive Weeds (https://edis.ifas.ufl.edu/publication/IN607) and the Technical Advisory Group for Biological Control Agents of Weeds Manual. 


\section{Summary}

While this overview of the process of developing a biological control of weeds agent is not all-inclusive, it illustrates the care that scientists and regulators dedicate to this process to ensure that organisms released for the biological control of weeds are safe and effective. The use of biological control to reduce the spread and impact of invasive plants has been determined to be safe (Hinz et al. 2019) and both environmentally (Schwarzländer et al. 2018) and economically (Naranjo et al. 2015) effective.

\section{Literature Cited}

Ahmad, S. 2012. Herbivorous Insects: Host-Seeking Behavior and Mechanisms. Elsevier.

Amsellem, L., J. L. Noyer, T. Le Bourgeois, and M. Hossaert-Mckey. 2000. "Comparison of Genetic Diversity of the Invasive Weed Rubus alceifolius Poir.(Rosaceae) in Its Native Range and in Areas of introduction, Using Amplified Fragment Length Polymorphism (AFLP) Markers." Molecular Ecology 9 (4): 443-455. https://doi. org/10.1046/j.1365-294x.2000.00876.x

Asmare, E. 2017. "Current Trend of Water Hyacinth Expansion and Its Consequence on the Fisheries around North Eastern Part of Lake Tana, Ethiopia." Journal of Biodiversity and Endangered Species 5 (02): 189. https:// doi.org/10.4172/2332-2543.1000189

Boevé, J.L., R. Rozenberg, F. Mc Kay, and G. S. Wheeler. 2018. "Toxic Peptides in Populations of Two Pergid Sawflies, Potential Biocontrol Agents of Brazilian Peppertree." Journal of Chemical Ecology 44 (12): 1139-1145. https:// doi.org/10.1007/s10886-018-1021-6

Cuda, J. P. 2016. "Novel Approaches for Reversible Field Releases of Candidate Weed Biological Control Agents: Putting the Genie back into the Bottle." In Biological And Environmental Hazards, Risks And Disasters, edited by J. F. Shroder and R. Sivanpillai, 137-152.. Amsterdam: Elsevier, Inc. http://dx.doi.org/10.1016/B978-0-12-394847-2.00010-3

Hinz, H. L., R. L. Winston, and M. Schwarzländer. 2019. "How safe is weed biological control? A global review of direct nontarget attack.” The Quarterly Review of Biology 94 (1): 1-27. https://doi.org/10.1086/702340
Lazzaro, L., F. Essl, A. Lugliè, B. M. Padedda, P. Pyšek, and G. Brundu. 2018. "Invasive Alien Plant Impacts on Human Health and Well-Being." Invasive Species and Human Health 13 (10): 16. https://doi. org/10.1079/9781786390981.0016

Minteer, C. R., M. C. Smith, P. Madeira, C. Goosem, R. Zonneveld, J. Makinson, G. S. Wheeler, and M. Purcell. 2020. "Is biological control for earleaf acacia (Acacia auriculiformis) Feasible in the United States?" [Review]. Biocontrol Science and Technology 30 (12): 1275-1299. https://doi.org/10.1080/09583157.2020.1833305

Naranjo, S. E., P. C. Ellsworth, and G. B. Frisvold. 2015. Economic Value of Biological Control in Integrated Pest Management of Managed Plant Systems." Annual Review of Entomology 60. https://doi.org/10.1146/ annurev-ento-010814-021005

Overholt, W. A., R. Diaz, E. Rosskopf, S. J. Green, and W. A. Overholt. 2015. "Deep Characterization of the Microbiomes of Calophya spp.(Hemiptera: Calophyidae) Gall-Inducing Psyllids Reveals the Absence of Plant Pathogenic Bacteria and Three Dominant Endosymbionts." PLoS One 10 (7): e0132248. https://doi.org/10.1371/journal.pone.0132248

Qi, S.-S., Z. -C. Dai, D. -L. Zhai, S. -C. Chen, C. -C. Si, P. Huang, R. P. Wang, Q. X. Zhong, and D. L. Du. 2014. "Curvilinear Effects of Invasive Plants on Plant Diversity: Plant Community Invaded by Sphagneticola trilobata." PLoS One 9 (11): e113964. https://doi.org/10.1371/journal. pone.0113964

Salaudeen, T., M. Thomas, D. Harding, and S. D. Hight. 2013. "Economic Impact of Tropical Soda Apple (Solanum viarum) on Florida Cattle Production." Weed Technology 27 (2): 389-394. https://doi.org/10.1614/WT-D-12-00027.1

Schultheis, E. H., and D. J. MacGuigan. 2018. "Competitive Ability, not Tolerance, May Explain Success of Invasive Plants over Natives." Biological Invasions 20 (10): 2793-2806. https://doi.org/10.1007/s10530-018-1733-0

Schwarzländer, M., H. L. Hinz, R. Winston, and M. Day. 2018. "Biological Control of Weeds: An Analysis of Introductions, Rates of Establishment and Estimates of Success, Worldwide. BioControl 63 (3): 319-331. https:// doi.org/10.1007/s10526-018-9890-8 
Sheppard, A. W., R. D. Van Klinken, and T. A. Heard. 2005. Scientific Advances in the Analysis of Direct Risks of Weed Biological Control Agents to Nontarget Plants." Biological control 35 (3): 215-226. https://doi.org/10.1016/j.

biocontrol.2005.05.010

USDA-APHIS. 2019. Technical Advisory Group for Biological Control Agents of Weeds Manual. USDA-APHIS.

Wapshere, A. 1974. "A Strategy for Evaluating the Safety of Organisms for Biological Weed Control." Annals of Applied Biology 77 (2): 201-211. https://doi. org/10.1111/j.1744-7348.1974.tb06886.x 